\section{The case for high-energy physics}

SIR-Is the impression of being second rate of greater concern than the actuality? That is one of the conclusions that may be drawn from the article by John Maddox (Nature 329, 759; 1987) musing on the question whether Britain should withdraw from CERN (the European Organisation for Nuclear Research, see also p. 433).

The article advocates that Britain should pay its subscription yet refuse to provide high-energy physicists with the sums said to be needed "to make full use of the opportunity created by CERN membership". Such a course would not salvage our reputation as first-class scientists; we are assessed by results, not by whether or not we stick to treaties.

In such an atmosphere, few new physicists would risk their careers in our field, and so it would dry up. Once dead, it is hard to imagine it ever being reborn. Some endeavours simply cannot be run by market forces - among them, it seems, even markets themselves.

There is no point in debating whether money liberated from high-energy physics would indeed go to support the host of undeniably worthwhile projects in biology, chemistry and other fields of physics now reprehensibly being starved of funds. This possibility may have been fostered deliberately to divide the scientific community and thereby to make cuts within science seem self-inflicted.

The present assault on high-energy physics comes not so much from a rational assessment of society and civilization's long-term needs, but from a more general lack of comprehension, by this and previous governments, of the role of science in the modern world, which have picked the easiest targets - astrophysics, particle physics and even oceanography.

There is also little point in indignation at the strange assertions in the article, surely intended to convince the reader that high-energy physicists are profligate and financially irresponsible in these stringent times. In fact, CERN decided on LEP ten years ago, and is not "embarking" on its construction. And LEP was never intended to look for "string particles", offered as the theoretical star guiding us experimentalists. Its aims are far less esoteric and much more worthwhile. LEP is generally acknowledged to be the machine of choice for testing the Standard Model to its limits.

To claim that the benefits of LEP have never been proclaimed is untrue. Of course we know "what high-energy physics is for" - it is to study the structure and forces of the Universe at extremely small distances or equivalently high energy. What we don't know are the answers: if we did, but only then, high-energy physics would be redundant.
To dig beneath the "huff and puff", I can tell you why high-energy physics is a justifiable intellectual pursuit. It is one of the several areas of science whose goal is to to try to extend humankind's knowledge of the Universe and of our role therein. By probing structure to eversmaller distances, we are studying effects and phenomena that prevailed at the beginning of the Universe, and which have determined its development ever since.

By digging deeper, we discover that seemingly disparate phenomena are really manifestations of the same underlying truth, much as Maxwell's work embodied the unification of electricity and magnetism. The generally benign effects of electromagnetic technology in society have been a direct result.

The technological fruit of pure research is not, however, strictly relevant. Highenergy physicists believe that a vigorous search for knowledge brings its own rewards, both for individuals and society. To renounce the inquisitive drive is to accept our present prejudices and misapprehensions. It is to renounce the ideals of creative curiosity and consumerism, it is less from arrogance and more from our perhaps naive lack of comprehension that people might not find it as beautiful a subject as we do. And then there is the fact that staying at the front requires all one's energies.

\section{Blackett Laboratory,}

Imperial College of Science and

Technology,

London SW7 2BZ, UK

John Maddox writes: The article complained of concluded that "the British government's best course is to stay a member of CERN, but to let high-energy physics grants take their chances with others at peer-review meetings".

\section{First World guilt}

SIR-Any possible responsibility of the United States in the poverty of underdeveloped countries was denied by Jocelyn Tomkin (Nature 329, 10; 1987) with the naive argument that, should America disappear from the Earth, "World market prices of raw materials and crops would collapse, a major source of sustenance for third world countries would be withdrawn and, far from rising out of poverty, they would sink into deeper poverty". Exactly as the fact that babies need parents' help does not demonstrate that parents are not or cannot be violent against babies, the fact that the First World buys things from the Third does not demonstrate that it cannot be responsible for its poverty. Furthermore, Tomkin did not add any reference to support the implicit statement that the 'First World' is of benefit to the Third.

It is true instead that developed countries receive from underdeveloped ones more than they give, so that world's money flows upstream from the poorer to the richer. This is made possible, in spite of the helps and loans that the First World gives to the Third, by the huge amounts of money our industries, companies and agroindustrial complexes earn from lowcost plants sited in developing countries ${ }^{1.2}$; let me only quote the Union Carbide plant in Bhopal, which has become tragically known only by chance.

If the advantages the First World obtains from the Third were not so large it would be very difficult to explain why countries rich in natural resources (petroleum, metals, diamonds, agriculture) can be very poor.

It is impossible to discuss here the economic relationships between developed and underdeveloped countries, but there is little doubt that underdevelopment is a cultural reality more than an economic one. The end result of a cooperation in which the Third World gives its nonrenewable resources and the First its renewable technology is that the United States and Europe consume one third of the total products.

Maybe the scientific community cannot do very much to modify these large-scale economic equilibria, but it is important at least to be aware that developed countries are partially responsible for the poverty of developing ones.

Andrea Bellelli

P. Trasimeno 2, 00198 Roma, Italy

1. George, S. Comment meurt l'autre Moitie du Monde (Laffont, Paris, 1978)

. Gentilini, M. \& Duflo, B. Medicine Tropicale (Flammarion, Paris, 1977).

3. Cross, N. New Scient. 114, 34 (1987).

\section{Mistaken identity}

SIR-Dreams really might come true if certain persons are in "competition to emulate President Theodore Roosevelt's fatuities on the similar [stock market crash] events of 1929" (Nature 330, 1; 1987): the poor chap had been dead for 10 years! President Reagan's other, more vital, counterpart in the crash of 1929 was President Herbert C. Hoover (no relation to Edgar J.), who was defeated in 1932 by Franklin D. Roosevelt who, in turn, went on to launch the New Deal and was handsomely re-elected for his efforts in 1936. Would that Senator Robert Dole, despite his lack of famous namesakes, have similar success to Roosevelt (the vital one) in his proposed presidential legislative programme for 1989 !

JAI Press, 3 Henrietta Street,

Piers R. Allen

London WC2E 8LU, UK 